\title{
THE EFFECT OF TRANSCRIPTION INHIBITORS ON UPTAKE OF URACIL AND URIDINE BY SCHIZOSACCHAROMYCES POMBE
}

by

\author{
BIRTE KRAMHØFT1) \\ and
}

HELGE A. ANDERSEN2)

\begin{abstract}
Biological Institute of the Carlsberg Foundation
1) Institute of Biological Chemistry A, Universitetsparken 13, DK-2100 Copenhagen Ø

2) Department of Biochemistry $B$, Panum Institute, Blegdamsvej 3C, DK-2200 Copenhagen N
\end{abstract}

Keywords: Tetrahymena peptide, Actinomycin D, pool-regulation

The effect of Tetrahymena derived inhibitor peptide(s) and Actinomycin D on uptake and incorporation of uracil and uridine in Schizosaccharomyces has been studied. It was found that the two transcription inhibitors initially caused some stimulation of uptake of both RNA precursors. With time Tetrahymena peptide reduced the rate of uridine uptake and incorporation dramatically, whereas the effect on uracil uptake and incorporation was much less pronounced. In the presence of Actinomycin D uptake of both precursors was stimulated even at a time when a reduced amount of incorporated label was observed.

\section{INTRODUCTION}

It has previously been described that (a) small peptide(s) secreted by the ciliated protozoan Tetrahymena pyriformis reduce the rate of RNA synthesis in the fission yeast Schizosaccharomyces pombe $(1,4,5)$. This was measured chemically as well as by use of radioactive RNA precursors. However, the observed effect of the Tetrahymena peptide differed when the rate of RNA synthesis was measured by use of different labelled precursors. Thus, in exponentially mul- tiplying cultures, the rate of incorporation of ${ }^{14} \mathrm{C}$-uracil and ${ }^{32} \mathrm{P}$-phosphate into acid-insoluble material was reduced by $15-20 \%$, whereas the rate of ${ }^{14} \mathrm{C}$-uridine incorporation was reduced by $50-70 \%$ under the same experimental conditions (4).

Like Tetrahymena peptide(s) the peptide antibiotic Actinomycin D reduced RNA synthesis in Schizosaccharomyces $(5,7)$. It was reported by MITCHISON and coworkers that uridine incor- 
poration was affected differently from the other RNA precursors used, and they suggested that Actinomycin D not only affected transcription but also had a special effect on uridine uptake and/or incorporation (7). On this background we suggested that the different degree of inhibition of uracil and uridine incorporation by Tetrahymena peptide could be due to a special effect of this inhibitor on the uptake of uridine (4).

In the present paper we have investigated the effect of Tetrahymena peptide and Actinomycin $D$ on uracil and uridine uptake by exponentially multiplying Schizosaccharomyces pombe cells. It is shown that both peptides affect the uptake of RNA precursors and it is suggested that this is a consequence of secondary, pool mediated regulations of the uptake following a reduced rate of transcription, rather than a direct interaction of the peptides with transport mechanisms.

\section{MATERIALS AND METHODS}

Cultures of the fission yeast Schizosaccharomyces pombe, strain $972 \mathrm{~h}$ - (haploid wild type) were grown in complex nutrient broth, YEG, composed of $0.5 \%$ yeast extract (Difco) and $3 \%$ glucose. Except when otherwise indicated, uptake of radioactive uridine or uracil was determined in the following way, essentially according to the principles in Mitchison and Gross (6) and Cummins and Mitchison (3):

Cultures were grown to a cell density of about $30 \times 106 / \mathrm{ml}$ (about 2 cell generations prior to entry into stationary phase) and divided in parallel portions of $20.0 \mathrm{ml}$. Partially purified Tetrahymena peptide $(40 \mu \mathrm{l} / \mathrm{ml})$ or Actinomycin $\mathrm{D}$ (Calbiochem, $20 \mu \mathrm{g} / \mathrm{ml}$ ) was added at the appropiate time points. Tetrahymena peptide was prepared as described by ANDERSEN et al. (2) and partially purified on a G25 Sephadex column (Pharmacia) in order to remove low molecular weight substances.

Just prior to each uptake experiment the cultures were transferred to small beakers and stirred using a magnetic stirrer. At time zero radioactivity $(0.13 \mu \mathrm{Ci} / \mathrm{ml})$ of ${ }^{14} \mathrm{C}$-uridine or ${ }^{14} \mathrm{C}$ uracil (Amersham, spec.act. $58 \mathrm{mCi} / \mathrm{mmole}$ in both cases) was added and samples were drawn alternately with a $1.0 \mathrm{ml}$ automatic pipette for the determination of total radioactivity taken up and the amount incorporated into acid-insoluble material, respectively. Incorporation was stopped by pipetting the samples into vials containing $1 \mathrm{ml}$ ice cold $20 \mathrm{~mm}$-uridine or $5 \mathrm{~mm}$ uracil for the determination of total uptake and the same concentrations of uridine and uracil in $1 \mathrm{ml} \mathrm{10 \%} \mathrm{TCA} \mathrm{(trichloroacetic} \mathrm{acid)} \mathrm{for} \mathrm{the} \mathrm{de-}$ termination of acid-insoluble counts. Each series of sampling lasted less than $2 \mathrm{~min}$. Thus, changes in the temperature and, consequently, uptake rates could be ignored. After the termination of the experiment the samples were filtered and washed with the appropiate washing solutions: $10 \mathrm{~mm}$-uridine, $2.5 \mathrm{~mm}$-uracil or the same containing 5\% TCA. The amount of uracil or uridine in the YEG medium was estimated to be less than $0.1 \mathrm{~mm}$ as determined by isotope dilution. Control experiments revealed that only insignificant amounts of radioactive material was lost from the cells during the washes when the label was not precipitated with TCA. The samples were dried and then counted in a Beckmann Liquid Scintillation Counter model LS 200.

Prior to addition of radioactivity, $2 \times 1.0 \mathrm{ml}$ of the experimental culture was removed and fixed with $1.0 \mathrm{ml} 4 \%$ formaldehyde. Cell numbers were obtained from these samples after counting in a hemocytometer.

\section{RESULTS}

Figures 1 and 2 show the uptake and incorporation of ${ }^{14} \mathrm{C}$-labelled uracil and uridine, respectively, in cultures of Schizosaccharomyces which were treated with Tetrahymena peptide for 2 hours prior to addition of radioactive label. It is seen that in both cases total uptake and incorporation into acid-insoluble material are reduced by the peptide though more in the case of uridine (Figure $2 A$ and $B$ ) than in the case of uracil (Figure $1 \mathrm{~A}$ and $\mathrm{B}$ ).

The content of labelled uracil or uridine in the acid-soluble pool can be calculated by subtraction of the values in Figures IB and 2B (acidinsoluble counts) from the equivalent values in Figures $1 \mathrm{~A}$ and $2 \mathrm{~A}$ (total counts). The results are shown in Figures $1 \mathrm{C}$ and $2 \mathrm{C}$, respectively. It is seen that the pool of both the control and the treated cultures reaches a steady state level about 20 minutes after the addition of the labelled compounds. The amont of radioactivity in the 


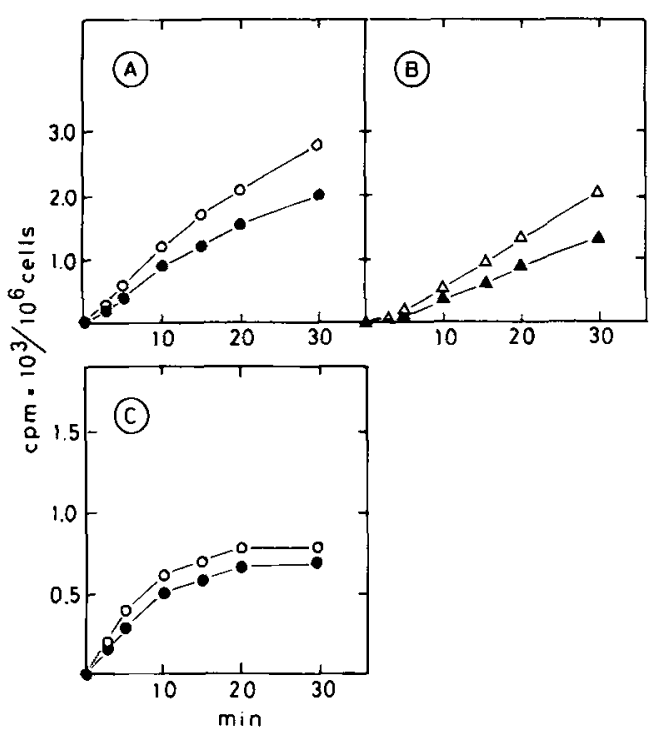

Figure 1. The effect of Tetrahymena peptide on uptake and incorporation of ${ }^{14} \mathrm{C}$-uracil in Schizosaccharomyces.

A: total amount of label taken up. B: label incorporated in the acid-insoluble material. C: label present in the cellular pool, calculated by subtraction of the values in $\mathrm{B}$ from the equivalent values in A. ${ }^{14} \mathrm{C}$-uracil was added at time zero. Tetrahymena peptide was added 2 hours prior to the experiment. $\bigcirc$ : controls, -: cells treated with Tetrahymena peptide.

uracil pool at steady state is reduced by Tetrahymena peptide to about $85 \%$ of the control value, whereas the amount of radioactive uridine in the pool of the treated cells is only $54 \%$ of the control value.

It may be seen from Figures 1 and 2 that the amount of radioactivity incorporated into acidinsoluble material during the first 2 minutes is

Figure 3. The effect of Tetrahymena peptide on the initial uptake of uridine (left set of frames) and uracil (right set of frames) at various time points after addition of the peptide.

Circles: the total amount of label taken up. Triangles: label incorporated in the acid-insoluble material. Controls: open symbols; treated cells: closed symbols. Radioactivity was added at time zero. Each frame represents one separate experiment on identical parallel cultures.

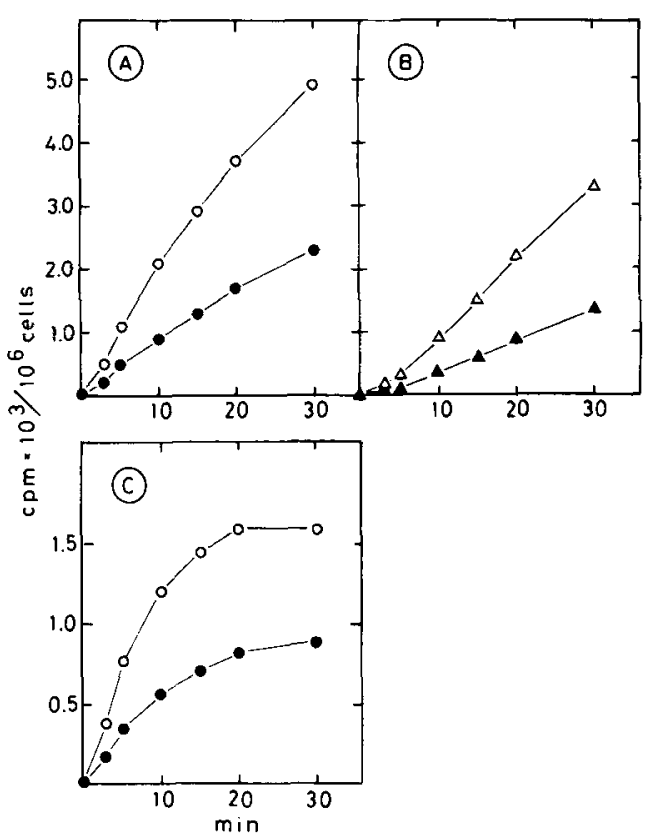

Figure 2. The effect of Tetrahymena peptide on uptake and incorporation of ${ }^{14} \mathrm{C}$-uridine in Schizosaccharomyces. Symbols and text as in Figure 1.

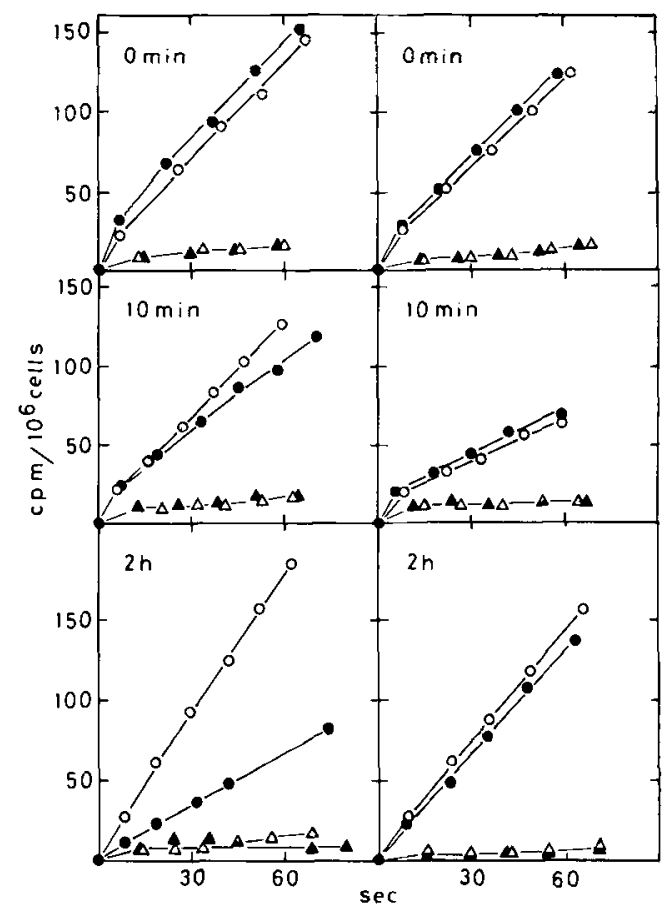


B. KRAMHøFI \& H.A. ANDERSEN: Uptake of RNA precursors by Schizosaccharomyces

Table I.

The effect of Tetrahymena peptide and Actinomycin D on initial uptakea) and incorporationa) of uridine and uracil by Schizosaccharomyces.

\begin{tabular}{|c|c|c|c|c|c|c|}
\hline \multirow[t]{2}{*}{ Time after addition of peptide } & \multicolumn{2}{|c|}{$0 \mathrm{~min}$} & \multicolumn{2}{|c|}{$10 \mathrm{~min}$} & \multicolumn{2}{|c|}{2 hours } \\
\hline & uptake & incorp. & uptake & incorp. & uptake & incorp. \\
\hline Tetrahymena peptide & 1.2 & 1.0 & 0.9 & 1.0 & 0.4 & 1.0 \\
\hline \multicolumn{7}{|l|}{ Uridine } \\
\hline Actinomycin D & 1.2 & 1.0 & - & - & 1.5 & 0.6 \\
\hline Tetrahymena peptide & 1.1 & 1.0 & 1.1 & 1.0 & 0.9 & 1.0 \\
\hline \multicolumn{7}{|l|}{ Uracil } \\
\hline Actinomycin D & 1.2 & 1.0 & - & - & 1.4 & 0.7 \\
\hline
\end{tabular}

a) Values are calculated as relative to the equivalent controls from readings at $30 \mathrm{sec}$ on the curves shown in Figures 3 and 4.

low relative to the total amount taken up. Therefore, the initial total uptake is probably a reasonably good measure of transport of uracil and uridine into the cells. In order to study the initial uptake of the RNA precursors, experiments were designed to allow rapid sampling within the first minute after addition of the radioactivity. The uptake experiments were carried out at various time points after addition of Tetrahymena peptide. The results are shown in Figure 3. Each

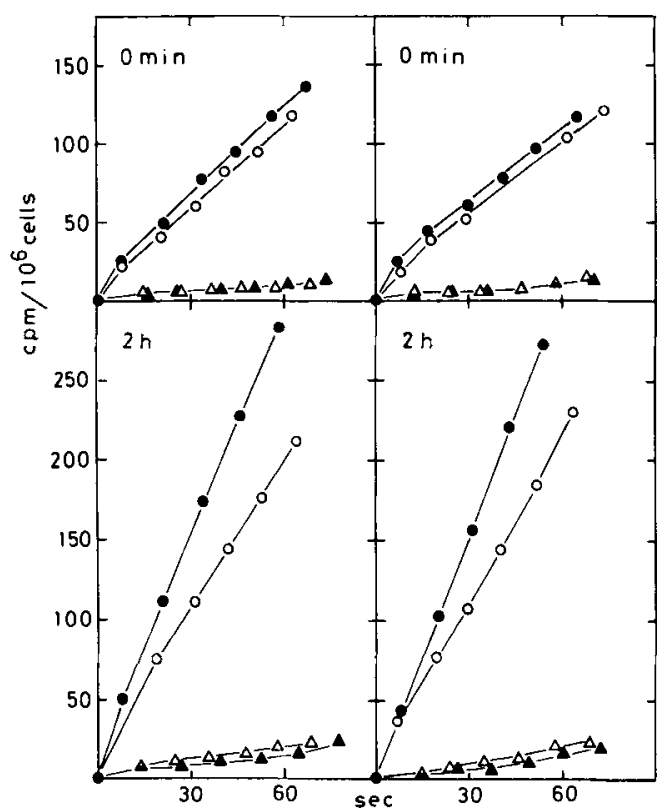

Figure 4. The effect of Actinomycin D on the initial uptake of uridine (left set of frames) and uracil (right set of frames). Text and symbols as in Figure 3. frame represents measurements on identical parallel cultures as described in section 2 . The results show (upper set of frames) that immediately after addition of Tetrahymena peptide the total uptake of both uridine (left frame) and uracil (right frame) tend to be increased. No difference in the amount of incorporated label could be detected at this time point. After 10 minutes in the presence of Tetrahymena peptide (middle set of frames) the total uptake of uridine is reduced compared to the control, whereas the uracil uptake is only slightly affected. Finally, after 2 hours in Tetrahymena peptide (lower set of frames) uridine uptake is strongly reduced whereas uracil uptake is only slightly reduced.

Assuming that the total amount of radioactivity taken up within the first minute reflects actual transport rates of precursor into the cells, the effect of the Tetrahymena peptide on transport and incorporation may be calculated. The results of such calculations are shown in Table $I$. It is seen that immediately after addition of the peptide, uptake of both uracil and uridine seem to be stimulated. After 2 hours in the presence of the peptide inhibitor uridine uptake is more than halved compared with the control while uracil uptake is only slightly affected.

As previously demonstrated $(5,7)$ the peptide antibiotic Actinomycin D reduces the rate of RNA synthesis in Schizosaccharomyces. In order to see if this inhibitor had a similar effect on the uptake of uridine and uracil as described above, experiments analogous to the ones depicted in Figure 3 were carried out with Actinomycin D. The results are shown in Figure 4. 
As shown (upper set of frames) the uptake of both uracil and uridine is initially somewhat increased (cf Table I). The uptake pattern at 10 minutes after addition of Actinomycin D resembles that shown for zero minutes (not shown). However, contrary to the effect of the Tetrahymena peptide inhibitor, 2 hours treatment with Actinomycin D strongly increases the uptake of both uracil and uridine (Figure 4, lower set of frames). It may be calculated from the uptake curves that the uptake is increased by a factor 1.4 (cf. Table I). In spite of the increase in total uptake, incorporation of both uracil and uridine into acid-insoluble material is reduced to about $66 \%$ of the control values indicating an actually reduced rate of transcription (Figure 4 , lower set of frames and Table I).

\section{DISCUSSION}

The results presented above show that in the presence of Tetrahymena peptide(s) uridine uptake and incorporation eventually become much reduced, whereas uracil uptake and incorporation is much less affected under identical experimental conditions. Actinomycin D affects both precursors in the same way, i.e. for both of them uptake is increased whereas incorporation is reduced.

Schizosaccharomyces growing in a complex nutrient broth as used here will utilize exogenous uridine and uracil as well as endogenously synthesized RNA precursors. The observations described here may therefore reflect l) a direct interaction of the inhibitor peptides with uptake mechanisms at the cell surface or with intracellular enzymes involved in precursor uptake, 2) the existence of regulatory mechanisms controlled by the actual rate of transcription, the effects on uptake thus being indirect. The fact that uridine uptake eventually becomes strongly reduced after addition of the Tetrahymena peptide(s) could indicate that this inhibitor in addition to the previously reported effects on transcription $(1,2,4,5)$ acts as a rather specific inhibitor of uridine transport. However, the slowly develop- ing effect on uridine uptake, with only a slight inhibition $10 \mathrm{~min}$ after addition of Tetrahymena peptide(s), makes a direct inhibition of transport mechanisms very unlikely. We therefore, favour the interpretation that the results obtained with both Tetrahymena peptide(s) and Actinomycin $\mathrm{D}$ are consequences of pool-mediated feed-back regulations of uptake following a reduced rate of transcription. Such regulation has previously been suggested to exist in Schizosaccharomyces with respect to adenine uptake (3).

\section{REFERENCES}

1. ANDERSEN, H.A. \& B. Kramhøft: Inhibition of RNA synthesis in yeast protoplasts by a peptide factor from Tetrahymena cells. Cell Biol. Intern. Rep. 5, 187-194 (1981)

2. ANdersen, H.A., A.E. LyKKesfeldt \& S.J. NIELSEN: On the role of small peptides in the regulation of RNA synthesis in Tetrahymena pyriformis. J. Cell Sci. 45, 31-39 (1980)

3. Cummins, J.E. \& J.M. Mitchison: Adenine uptake and pool formation in the fission yeast Schizosaccharomyces pombe. Biochem. Biophys. Acta 136, 108-120(1967)

4. Kramhøft, B. \& H.A. Andersen: Regulation of RNA synthesis in fission yeast. The effect of a Tetrahymena peptide factor on RNA synthesis in exponentially multiplying yeast cells. Cell Biol. Internatl. Rep. 5, 1019-1026 (1981)

5. KRAMHøFT, B. \& H.A. ANDERSEN: The role of low molecular weight peptides in the regulation of RNA synthesis in Schizosaccharomyces pombe. Carlsberg Res. Commun. 47, 275-283 (1982)

6. Mitchison, J.M \& P.R. Gross: Selective synthesis of messenger RNA in a fission yeast during a step-down, and its relation to the cell cycle. Exptl. Cell Res. 37, 259-277 (1982)

7. Mitchison, J.M., J. Creanor \& M.L. SarTIRANA: Enzyme synthesis, RNA synthesis and the effect of Actinomycin D in protoplasts of the fission yeast Schizosaccharomyces pombe. In: Yeast, Mold and Plant Protoplasts, J.R. Villanueva, J. Garcia-Acha, S. Bascón \& F. Uruburu eds., New York and London, Academic Press, pp. 229-247 (1973) 